\title{
Novel Method for Controlling Cerebrospinal Fluid Flow and Intracranial Pressure by Use of a Tandem Shunt-Valve System
}

\author{
Yasuo Aihara \\ Department of Neurosurgery, Tokyo Women's Medical University, Tokyo, \\ Japan
}

\section{Introduction}

In general, cerebrospinal fluid (CSF) shunt valves control the intracranial pressure rather than fluid flow or other aspects. ${ }^{1-4}$ There are various kinds of shunt valves including fixed pressure and programmable valves. Fixed pressure valves usually have low, medium or high pressure settings. The choice of valve pressure is based on preoperative intracranial pressure, clinical course, cerebral ventricle size, age, and the lifestyle of the patient. ${ }^{5-8}$

Programmable valves with or without anti-siphon devices were subsequently developed. 9-16 CSF flow is regulated by adjusting the pressure via a magnetically-controlled valve. However, CSF dynamics are complicated because production and absorption rates of CSF may vary in any given patient. Consequently, the existing shunt systems cannot correspond to each of these situations. With regard to intracranial pressure; treatment in vivo involves not only setting the shunt's valve pressure but also taking into consideration the CSF flow rate; which is a very important parameter. 17,18 . Even with anti-siphon devices attached to some valves, despite their advantages, there is still no perfect valve system in neurosurgery as devices with these attachments still fail to adequately control pressure requirements as well as CSF flow rates at the same time. Practically, we sometimes experience a patient with over-drainage problem even using an anti-siphon device.

To overcome the difficulties of the existing shunt valve systems in achieving adequate CSF pressure and flow control, we contrived a novel tandem shunt valve system. We performed in vitro experiments using a manometer, and report the first clinical application of the novel tandem shunt system in humans.

\section{Material and methods}

An in vitro system with a manometer was built to measure pressure and flow rates of water in open and closed systems using the Codman (Codman; Johnson \& Johnson Co., Raynham) Hakim programmable valve (CHPV) and the STRATA programmable valve (Medtronic, Inc, Minneapolis) as shown in figures 1 and 2, respectively. Single (Fig. 1a and Fig. 2a) and two single shunt valves (Fig. $1 \mathrm{~b}$ and Fig. $2 \mathrm{~b}$ ) connected in series (the tandem shunt system) were connected to the manometer to check the pressure. 


\section{Water bath Manometer:M1}

a)

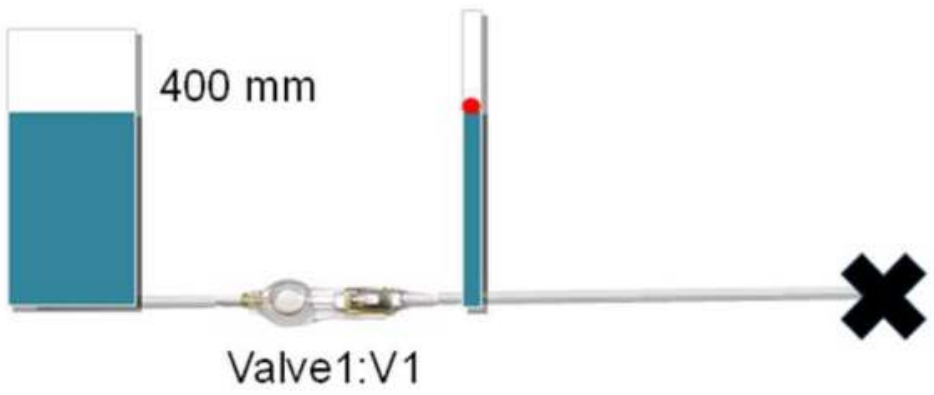

Water bath

Manometer:M1

b)

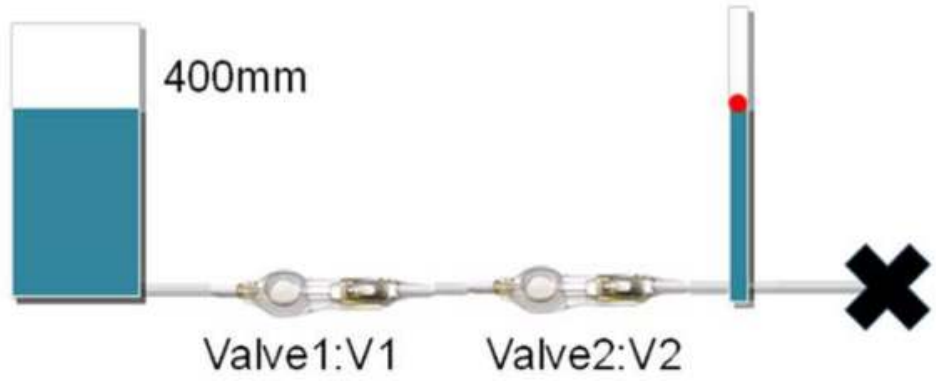

Top (1a): single shunt valve setup with clamp to close the system.

Bottom (2b): closed setup with two shunt valves connected in series (tandem shunt valve system) with clamp to close the system.

Fig. 1. In Vitro closed system with Codman (Codman; Johnson \& Johnson Co., Raynham) Hakim programmable valves (CHPV)

\subsection{In vitro closed system with water bath (Fig. 1)}

In the closed single shunt valve system experiment, as shown in figure 1a, we measured the pressure in the original bath to be $400 \mathrm{mmH}_{2} \mathrm{O}$ with a closed valve (V1). We conducted 3 changes to $\mathrm{V} 1$, the valve pressure of the CHPV, and took 5 measurements each at $\mathrm{V} 1=50$, $\mathrm{V} 1=100$ and $V 1=200$. Figure $1 \mathrm{~b}$ shows the setup in a closed tandem shunt valve system. If we set $\mathrm{V} 1=50$ and $\mathrm{V} 2=50$, the total pressure setting of the valves $(\mathrm{V})$ is $\mathrm{V} 1+\mathrm{V} 2=100$. Other combinations of $\mathrm{V} 1$ and $\mathrm{V} 2$ were taken and six are reported below.

\subsection{In vitro open system with manometer (Fig. 2)}

An open system represents the real world environment. Unlike figure $1 \mathrm{a}$ and figure $1 \mathrm{~b}$, figure 2 does not have a clamp at the endpoint to keep the system closed. In our experiment we have the STRATA valve directly connected to the manometer and a scale at the other 
a)

\section{$400 \mathrm{~mm}$}

\section{Manometer}

\section{Valve1: 1}

b)

$400 \mathrm{~mm}$

Manometer

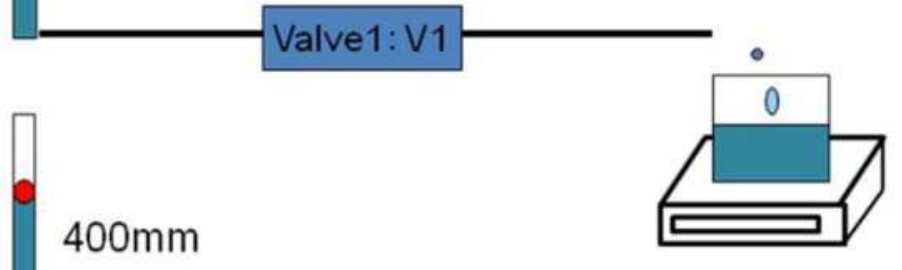

\section{Electric volume meter}

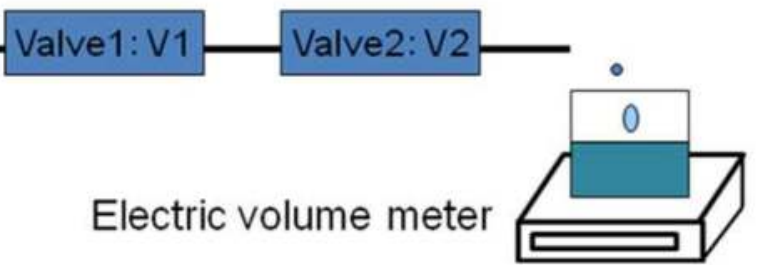

Top (2a): Manometer connected to the single shunt valve with a scale on the opposite end to measure volume of water over time.

Bottom $(2 b)$ : the inclusion of another STRATA shunt valve connected in series was the only change made to the system.

Fig. 2. In Vitro Open system with STRATA programmable valves (Medtronic, Inc, Minneapolis)

end to measure the volume of water as seen in figure 2. In our single valve open system experiment the manometer was set to $400 \mathrm{mmH}_{2} \mathrm{O}$ and the STRATA valve used had 5 programmable settings $(0.5,1.0,1.5,2.0$, and 2.5$)$. These are referred to as performance levels (PL) by STRATA and we took manometer readings at each PL. An electric flow meter was also used to measure the volume of water every 30 seconds for each PL. The same measurements for the open tandem shunt valve system (Fig. 2b) were also taken but for different combinations of PLs. This experiment helped us illustrate the effects of a tandem shunt valve system in hydrocephalus cases. 


\section{Results}

\subsection{In vitro closed system with water bath}

In the single shunt valve system experiment, when V1 was adjusted to 50, the final measurement in the manometer equaled around $350 \mathrm{mmH}_{2} \mathrm{O}$ (Fig. 3a). When V1=100, the final manometer reading was around $300 \mathrm{mmH}_{2} \mathrm{O}$. Subsequently a V1 adjustment of 200 resulted in a final manometer reading of around $200 \mathrm{mmH}_{2} \mathrm{O}$. Based on these results, we can conclude that the original water bath pressure $=\mathrm{V} 1$ pressure value + final manometer value (M1) as shown in figure $3 a$, where the average results of 5 measurements at (V1=50, 100 and 200) were taken. In the closed tandem shunt valve system experiment, when the final manometer reading was $300 \mathrm{mmH}_{2} \mathrm{O}$, the sum of $\mathrm{V} 1+\mathrm{V} 2$ always equaled around 100 . We conducted further experiments that measured five manometer readings at different combinations of V1 and V2 such that (V1 + V2 = 100, 150, 200, 250, 300 and 400) and averaged the results as summarized in figure $3 \mathrm{~b}$. Based on our experiment, the final manometer pressure is the original water bath pressure minus (V1+V2). This principal holds for any value of V1 and V2. In conclusion, when two valves (Fig. 1b) are connected in series, regardless of whether one is higher than the other, their sum will always behave in the same way as the one valve in the closed system as shown in figure 1a.

\subsection{In vitro open system with manometer}

In an open system, at any value of V1, the manometer represents the same value as V1. At PL of 0.5 on the STRATA valve the final manometer reading was approximately $30 \mathrm{mmH}_{2} \mathrm{O}$ after we had allowed the system to run for some time. Subsequent PL settings were measured and their final pressure manometer readings are as follow: $1.0 \cong 40 \mathrm{mmH}_{2} \mathrm{O}$; $1.5 \cong 100 \mathrm{mmH}_{2} \mathrm{O}, 2.0 \cong 170 \mathrm{mmH}_{2} \mathrm{O}$, and $2.5 \cong 200 \mathrm{mmH}_{2} \mathrm{O}$ as seen in the legend of figure 4 . Figure 4 also shows the calculated flow rate $(\mathrm{ml} / \mathrm{min})$ curve over time. At the highest PL setting of 2.5 we achieved a lower flow rate as expected.

Figure $2 \mathrm{~b}$ shows two valves connected in series in an open system (tandem system). In our tandem valve open system experiment we varied V1 and V2 and measured the final manometer readings for each combination and a summarized table of results is shown in Table 1. Interestingly, in the tandem system, the final pressure was almost equal to the highest pressure setting of one of the valves in the system. In a single valve system the flow rate changed depending on the valve pressure (Fig. 4). On the other hand, the flow rate in the tandem system depends on the total pressure of each shunt valve setting (Fig. 5). Furthermore, based on our experiments, we concluded that in an open system, along with reducing the flow rate, we discovered that we could control pressure because the final pressure reading on the manometer was always equal to the highest pressure value of either V1 or V2.

We assessed all combinations of tandem shunt valve pressures. The result was that the flow rate depended on the total valve pressure in the system (Fig. 5). Of considerable significance in table 1 is the experiment with STRATA performance level $(1.0+1.0)$ and STRATA performance level (2.0). We would expect the final manometer pressure to be the same for these two experiments (because the PL totals are the same) but they are actually $50 \mathrm{mmH}_{2} 0$ and $170 \mathrm{mmH}_{2} 0$, respectively. There are two significant points here 1) flow rate and 2) final 


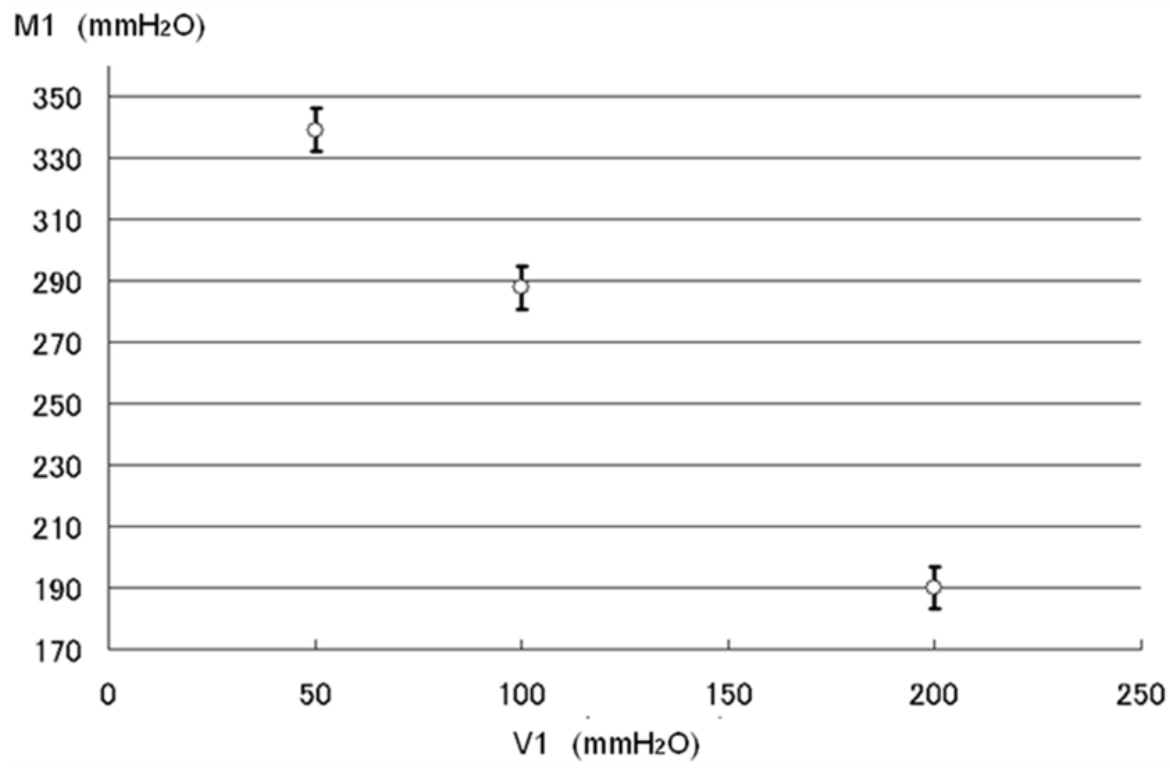

(a)

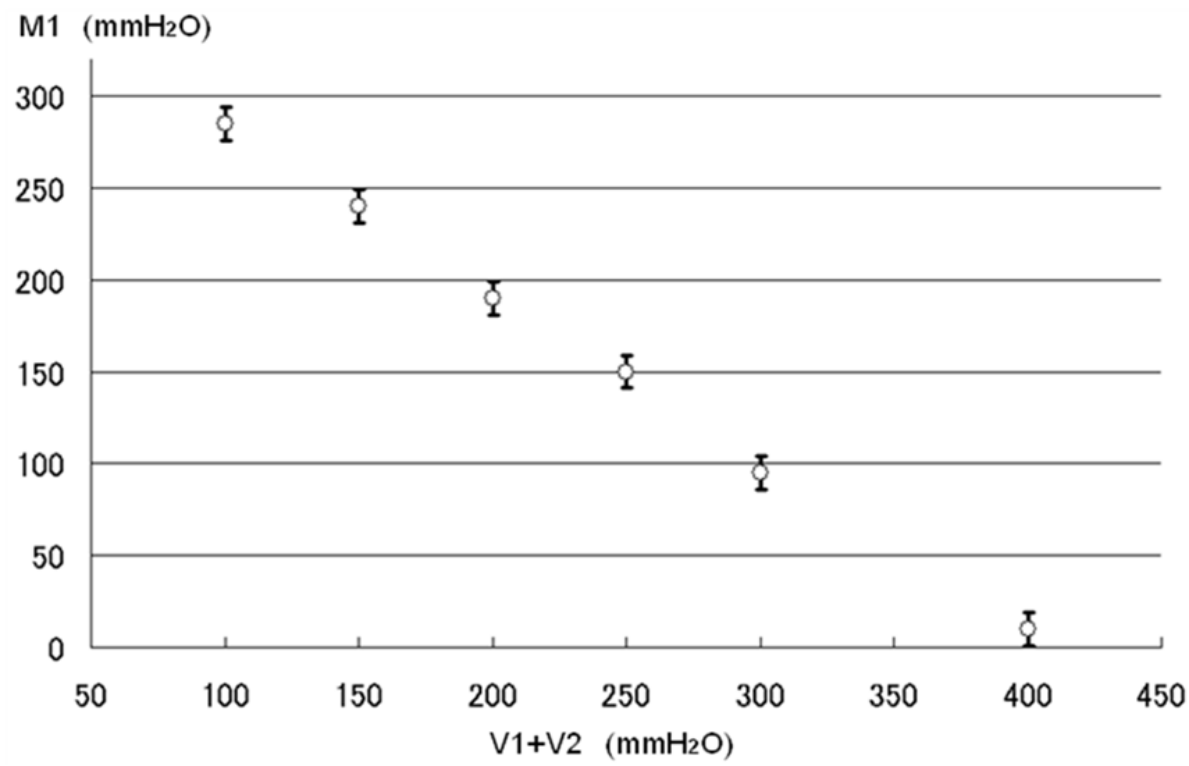

(b)

Demonstrating that the original water bath pressure $=\mathrm{V} 1$ pressure + final manometer reading (M1). With two valves connected in series, the following relationship continues to exist: original water bath pressure $=(\mathrm{V} 1$ pressure $+\mathrm{V} 2$ pressure $)+$ final manometer reading $(\mathrm{M} 1)$.

Fig. 3. (a) Single shunt valve experiment results for the closed system (b) Tandem shunt valve experiment results for the closed system 


\section{$(\mathrm{ml} / \mathrm{min})$}

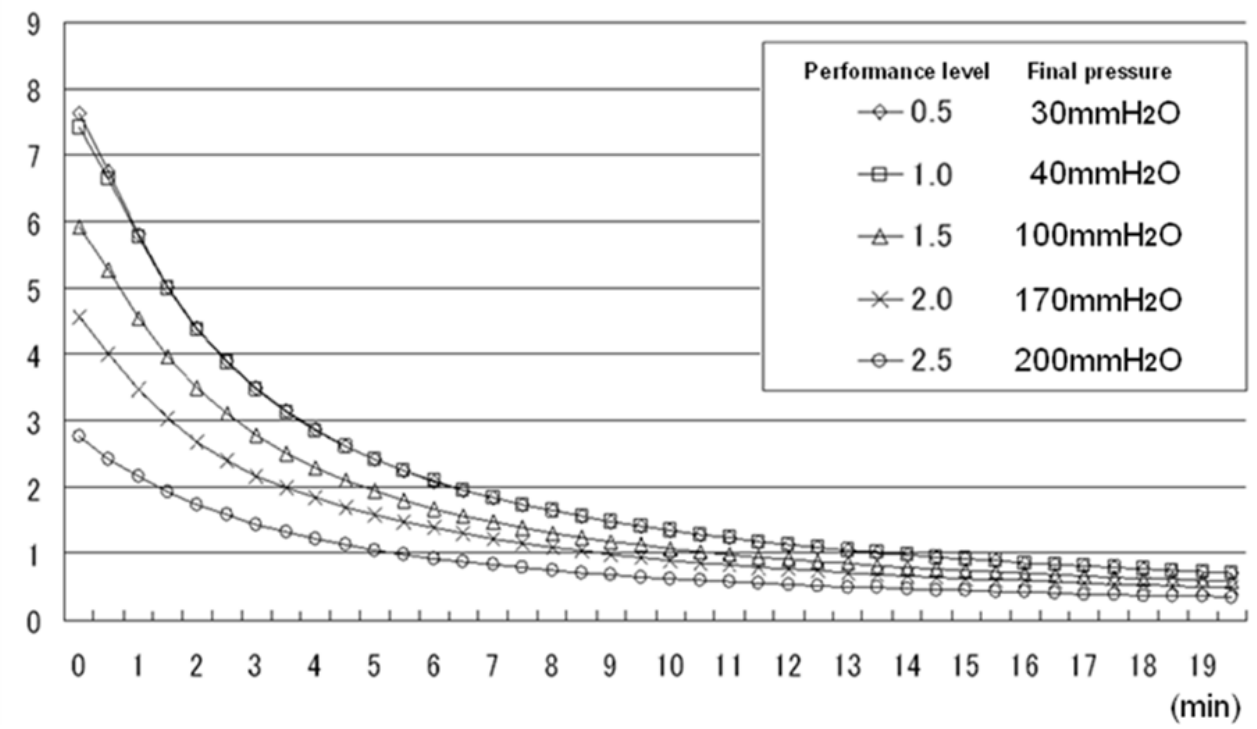

Each performance level setting on the STRATA valve corresponds to a final pressure reading as shown in the legend. Flow rate depends on shunt valve pressure setting.

Fig. 4. Single shunt valve experiment results for the open system

\begin{tabular}{|c|c|c|}
\hline Single Valve & Tandem Valve System & \\
\hline V1 (STRATA PL) & V2 (STRATA PL) & Final pressure \\
\hline 0.5 & - & $30 \mathrm{mmH}_{2} \mathrm{O}$ \\
\hline 1.0 & - & $40 \mathrm{mmH}_{2} \mathrm{O}$ \\
\hline 1.0 & 1.0 & $50 \mathrm{mmH}_{2} \mathrm{O}$ \\
\hline 1.5 & - & $100 \mathrm{mmH}_{2} \mathrm{O}$ \\
\hline 2.0 & - & $170 \mathrm{mmH}_{2} \mathrm{O}$ \\
\hline 2.0 & 0.5 & $180 \mathrm{mmH}_{2} \mathrm{O}$ \\
\hline 2.5 & - & $200 \mathrm{mmH}_{2} \mathrm{O}$ \\
\hline
\end{tabular}

\section{PL : performance level}

Table 1. Results comparing the Single shunt valve with Tandem shunt valve in the Open system. In the tandem system, with V1 at 1.0 and V2 at 1.0 the final pressure $(50 \mathrm{mmH} 2 \mathrm{O})$ is always close to the final pressure $(40 \mathrm{mmH} 2 \mathrm{O})$ when $\mathrm{V} 1$ is at 1.0 in a single valve system. 
pressure. From figure 5, if we compare the rate of decrease between the two experiments we find that the curves follow similar flow rates, which indicates that even at different pressures we can control the flow rate. In fact, at PL $(1.0+1.0)$, the final pressure of $50 \mathrm{mmH}_{2} 0$ is quite similar to that of a single valve with PL (1.0), where pressure is $40 \mathrm{mmH}_{2} 0$ as shown in table 1 , but exhibits flow rates similar to PL (2.0). Similarly compare the experiments where performance level $(2.0+0.5)$ with performance level $(2.5)$ and the same property exist.

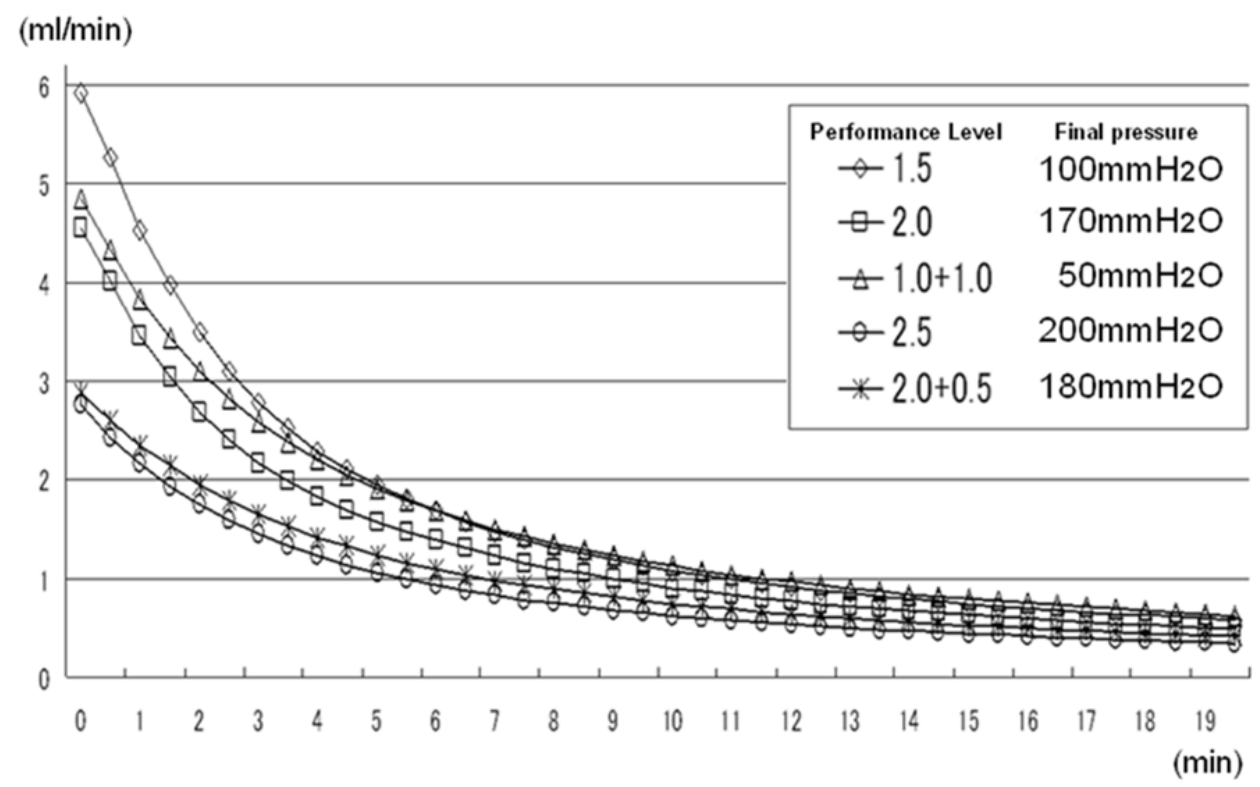

When the total performance levels are the same, the flow rates are similar. However, flow rates can decrease while maintaining final pressures.

Fig. 5. Tandem shunt valve experiment results for the open system

In conclusion, we can decrease flow rate without a major change in pressure using a tandem shunt valve system. After obtaining these in vitro results, we implemented tandem shunt valve systems in two shunt cases where problems associated with shunt implants such as slit like ventricle and or intractable hydrocephalus were present.

\section{Case 1}

A 6-year-old girl with a malignant glioma underwent bilateral ventricle-peritoneal (V-P) shunt (CHPV) for obstructive hydrocephalus. Although the patient's intracranial pressure was controlled by the shunt system (valve pressure was $150 \mathrm{mmH}_{2} \mathrm{O}$ ), hydrocephalus developed during chemotherapy and radiotherapy. The lateral ventricle size and abdominal circumference increased due to a peritoneal fluid collection caused by tumor tissue dissemination through the V-P shunt tract. The shunt valve pressure was adjusted from 150 to $180 \mathrm{mmH}_{2} \mathrm{O}$ to solve this over-drainage problem. However this caused acute 
hydrocephalus with deteriorating consciousness. The shunt valve pressure was decreased from 180 to $140 \mathrm{mmH}_{2} \mathrm{O}$. Although the ventricular size decreased and her consciousness improved, the fluid collection in the peritoneal cavity rapidly increased, which caused dyspnea due to high peritoneal pressure. We informed her parents about the two paradoxical problems that needed to be solved simultaneously, 1) finding the best V-P shunt valve pressure to prevent the hydrocephalus, and 2) reducing the amount of peritoneal fluid collection containing the brain tumor tissue and debris. To solve the opposing problems of obtaining sufficient CSF drainage to treat the hydrocephalus but not so much that it would cause peritoneal fluid collection, we tested the therapeutic possibility of the tandem shunt system by adding another adjustable valve (CHPV) with anti-siphon to the current setup. The new tandem shunt system was a connection from the lateral ventricle CHPV (1 $1^{\text {st }}$ valve) connected to the CHPV (2nd valve) with siphon guard to the peritoneal cavity. The performance level of the new tandem shunt system was adjusted to $140 \mathrm{mmH}_{2} \mathrm{O}$ for the $1^{\text {st }}$ valve and $100 \mathrm{mmH}_{2} \mathrm{O}$ for $2^{\text {nd }}$ valve. Hydrocephalus remarkably improved without peritoneal fluid collection and the patient was able to walk soon after the implant.

\section{Case 2}

A one and a half-year-old boy infected with Group B Streptococcus during pregnancy, born prematurely in July, 2007 at the gestational age of 28 weeks and weighing $1230 \mathrm{~g}$ presented with progressive enlargement of head circumference as compared with his body size. Ultrasonography and CT scans revealed hydrocephalus caused by subependymal hemorrhage and periventricular leukomalacia. After controlling intracranial pressure using the Ommaya reservoir, a V-P shunt (Programmable STRATA non siphon control (NSC) Valve) was implanted at the age of 98 days (42 weeks gestation). The intracranial pressure was well controlled at the programmable performance valve level of 1.5 . However, the performance level was changed to 2.5 (maximum pressure), because a CT scan showed slit lateral ventricles 6 months after the first shunt placement. After a temporary slight increase in size of the lateral ventricle, the patient was unable to keep a head-up position, which was judged to be a symptom of slit ventricles. Although an anti-siphon device (Delta chamber, Medtronic, Inc., Minneapolis) was added to the shunt system, which resulted in improvement of his symptoms for a month, he continued to suffer from depressed mood and loss of appetite in the head-up position. Moreover, he presented with acute hydrocephalus one day after the transient ligation of the shunt system to check the shunt system dependency. His parents were informed about the details of CSF over-drainage symptoms and the therapeutic possibility of tandem shunt valve system connection surgery. An extra adjustable STRATA NSC valve was connected to the previous shunt system. The final whole view of the tandem shunt valve system was a connection from the lateral ventricle to the STRATA NSC programmable valve (1 $1^{\text {st }}$ valve) connected to the STRATA NSC programmable valve (2nd valve) with anti-siphon system (Delta chamber) to the peritoneal cavity. The performance level of the new tandem shunt system was adjusted to 2.5 ( $1^{\text {st }}$ valve) and 0.5 ( $2^{\text {nd }}$ valve) but there was no remarkable change in his condition. After a few days, his second shunt valve performance level was adjusted from 0.5 to 1.0 and his general condition improved dramatically and he was able to keep head-up position over several hours. 


\section{Discussion}

Intra-ventricular cerebrospinal fluid, shunt valve opening pressure, and intra-abdominal pressure are, through common use in neurosurgery and convention, called ICP, valve pressure and abdominal pressure, respectively. If we also consider the tube connecting the head to the abdominal, a difference of water pressure is present, conventionally referred to as hydrostatic pressure. If we assume (ICP + hydrostatic pressure) - (valve pressure + abdominal pressure $)=0$, then this simplifies to ICP $=$ (valve pressure + abdominal pressure $)$ - hydrostatic pressure.

The difference in pressure causes fluid flow, however, other parameters to consider include the coefficient of viscosity caused by protein in the CSF, resistance between inner wall shunt tube and CSF flow (tube diameter), the positioning of the shunt valve (forehead or back of the head) and the intra-abdominal tube length and so on. All these parameters contribute to complicated flow dynamics, but a simpler approach is to only use pressures to help us describe fluid flow in a shunt system. In our in vitro experiment, we kept all other parameters the same and only changed pressure via valve settings and in the tandem shunt valve system, an additional shunt valve. This tandem system allowed us to precisely control the pressure and flow rate. Until now, CSF flow rate was always the result of the shunt's valve pressure but there has been no study to control the CSF flow rate and ICP individually. Our in vitro experiment showed that the tandem system was able to control CSF flow rate and ICP independently of each other.

Intracranial pressure automatically changes when the position of the head and abdominal changes (e.g. compare heights of standing versus sleeping person); these changes cause a siphon effect, which makes it extremely difficult to control ICP with only a single shunt system. ${ }^{19-21}$

Even with an anti-siphon system in place, controlling CSF flow is still difficult. However, with the tandem shunt valve system in place we were able to create a low CSF flow rate environment without increasing the intracranial pressure. In a single valve shunt system it was impossible to create such an environment while maintaining a constant ICP even with an anti-siphon system installed, because, as shown in our experiments, CSF flow is always directly related to the pressure setting at the valve. However, in the tandem valve shunt system, the most significant finding was that the final pressure was equal to the highest valve pressure of the two valves (Fig. 6). This means that in practice, this system has the possibility to control the intracranial pressure without increasing the pressure that is required by the patient.

Figure 6 demonstrates the mechanism behind the tandem shunt valves. It is used to show that the final pressure is equal to the highest valve pressure of the two tandem valves. M, V1 and V2 represent ICP in the human body, and the pressure settings at the shunt valve respectively. In M1 and M2 we add two walls V1 and V2 as shown in figure 6. It shows that regardless of where the highest wall is placed, the final water level at the highest wall will always be the same as the water level in column $M$. This demonstrates that the final pressure always equals the final pressures setting of either V1 or V2 (Fig 6a, b).

In terms of pressure management in the brain, when there are two valves present in a tandem shunt valve system, ICP pressure is controlled at the highest valve setting at the 
a)

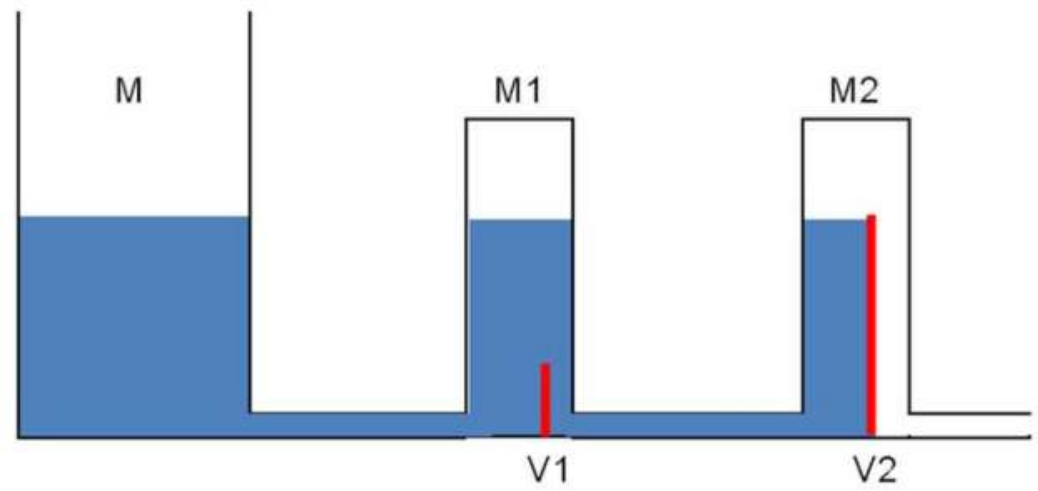

b)

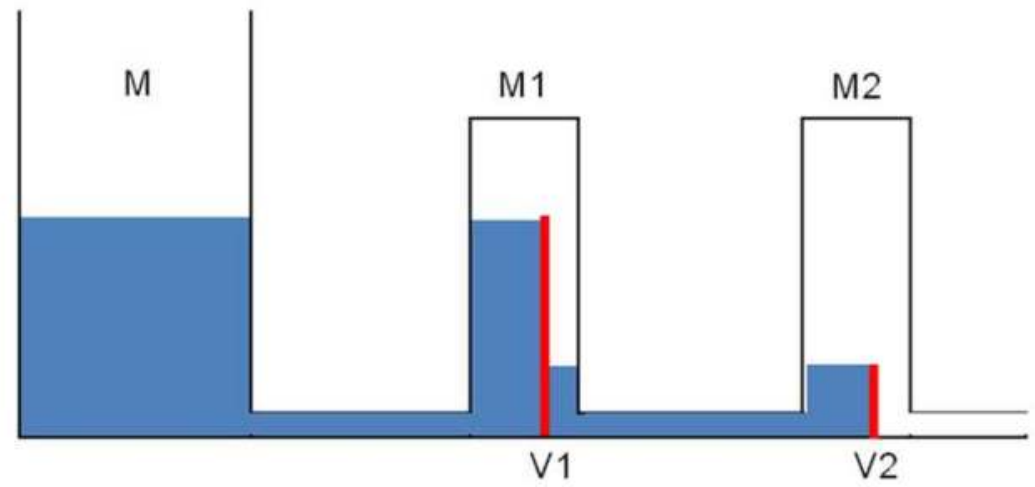

Top (6a): Liquid filled column system with two walls V1 and V2. Water level at M equals water level of V2 demonstrating that final pressure equals the pressure setting at the shunt, or in this case, height of the wall. M gauges pressure in this system, and represents ICP in the body.

Bottom (6b): Liquid filled column system with two walls V1 and V2 heights reversed. Water height at the highest wall is the same as the water height at M. Regardless of the ordering of V1 or V2, the final pressure will always equal to the highest pressure setting of either V1 and or V2. In real life ICP is controlled by the height of the highest setting of the two shunts.

Fig. 6. Controlling ICP - a special mechanism of tandem shunt valves 
shunt, while CSF flow rate is controlled by adjusting the valve settings. Until now, shunted patients in a single valve system have always been treated with respect to pressure. That is, we do not attempt to control the flow rate but attempt to control the pressure setting at the valve and flow rate is just a consequence of the pressure setting at the valve; that is higher pressure, lower CSF flow and vice versa. We have shown here that we can control CSF rate and ICP independently in the tandem shunt valve system.

Assume a performance level of 3.0 was required of a patient in a single shunt valve system using the STRATA valve. We could only do this by using 2 STRATA valves; the first (V1) connected to another STRATA (V2) shunt valve with the following V1 + V2 patterns available: $(2.5+0.5,2.0+1.0,1.5+1.5)$. Each of these patterns result in 1$)$ achieve the performance level of 3.0 and 2) set up the final ICP so that it would be controlled at 2.5, 2.0, and 1.5 (the highest valve pressure of the two valves). With only a single valve, the performance level of 3.0 would not be possible because the maximum performance level is 2.5. Furthermore, we were able to control the pressure while changing the flow rate with the tandem shunt valve system using the STRATA valves.

While the STRATA valve has only 5 settings, the CHPV has settings from 30 to 200 at increments of 10 . If we try to create a 250 environment with the CHPV, as required by the patient, it would be impossible to do so with only one valve. In a tandem system there are eight patterns available: $(200+50,190+60,180+70,170+80,160+90,150+100,140+110$, and $130+120$ ) with the CHPV shunt valve connected to another CHPV directly; creating a tandem shunt valve system. Each pattern could set up the final ICP controlled at 200, 190, $180,170,160,150,140$, and 130, respectively. These results would be the same condition as the STRATA example, that is, flow rate would be adjustable while keeping ICP controlled to the highest pressure setting of either V1 or V2. Because of the different combinations available we could select the best shunt valve pressure pair depending on the condition of the patient.

With the above mechanism, the tandem shunt valve systems (performance level $(2.5+1.0)$ ) prevent intracranial pressure to increase thereby decreasing cerebrospinal fluid flow as opposed to the single valve system performance level (2.5); which is extremely significant for treating slit-like ventricle. We can prevent an increasing ICP and limit flow rate at the same time, which is especially substantial for treating cases of over drainage. Our case studies have demonstrated that this control is only possible with a tandem shunt valve system in place and not a single valve system.

Given the associated problems that come with the usage of a single shunt, there will be a firm requirement for a shunt with tandem shunt valve properties in the future. Our mission is to assist development in this area is through the establishment of a new tandem shunt valve which contains two programmable valves in one device/chassis allowing for the best CSF flow and final ICP combination condition (Figure 7) in hydrocephalus patients. Since there have already been two successful clinical cases further studies to investigate clinical performance will only benefit hydrocephalus cases. The new tandem shunt valve system described here will provide future opportunities to achieve ICP pressure and CSF flow control in hydrocephalus and other related conditions requiring the prevention of pressure fall and fluid flow management at the same time. 


\section{Single valve + Single valve tandem system}

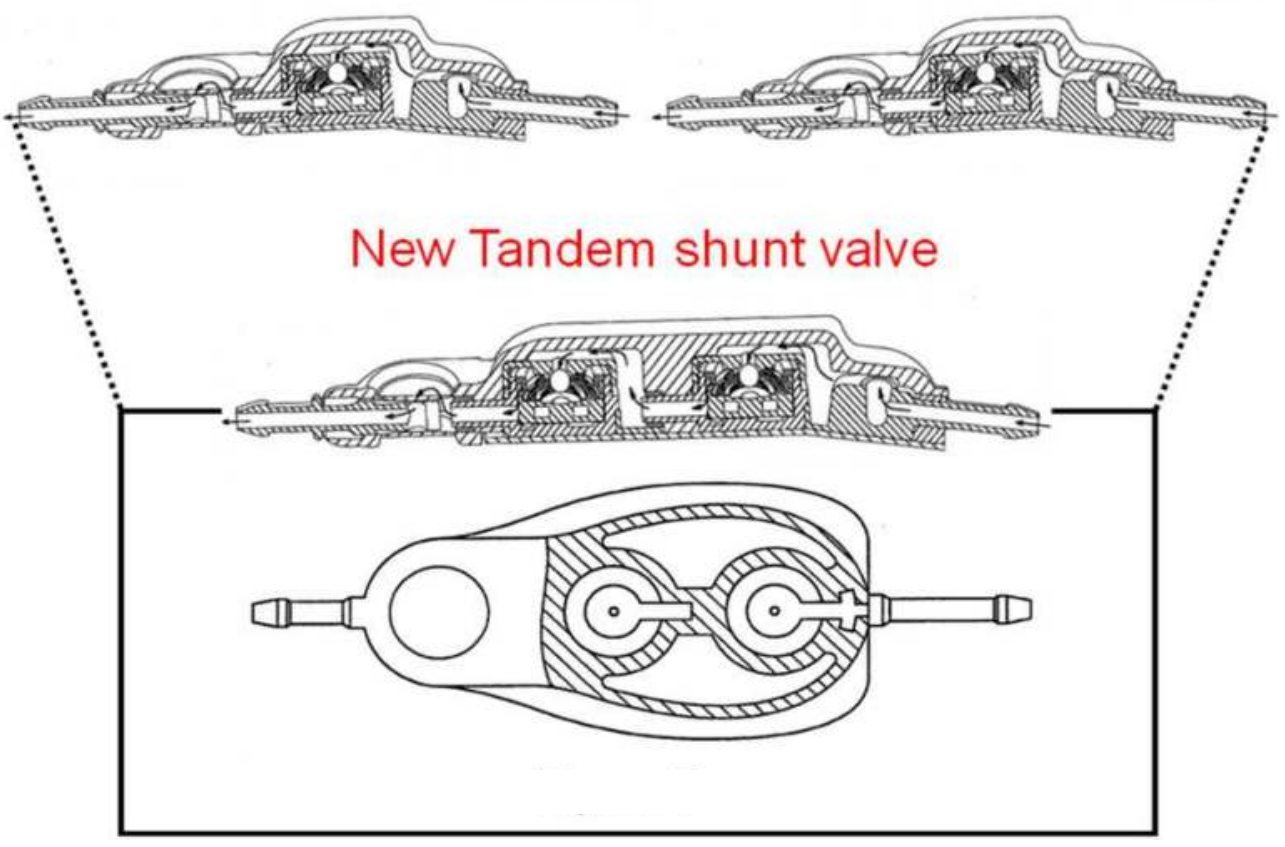

The best combination of the CSF flow and the final ICP condition is through a tandem shunt valve containing two programmable valves. This tandem shunt valve is compact and about the same size as today's single shunt valve.

Fig. 7. The new tandem shunt valve idea model

\section{References}

[1] Barnett, GH.; Hahn, JF.\& Palmer, J. (1987). Normal pressure hydrocephalus in children and young adults. Neurosurgery, 20: pp. 904-907.

[2] Black, PM. Hakim, R. \& Bailey, NO. (1994). The use of the Codman-Medos programmable Hakim valve in the management of patients with hydrocephalus: illustrative cases. Neurosurgery, 34: pp. 1110-1113.

[3] Faulhauer, K. \& Schmitz, P. (1978). Overdrainage phenomena in shunt treated hydrocephalus. Acta Neurochir 45: pp.89-101. 
[4] Hakim, S.(1973). Hydraulic and mechanical mis-matching of valve shunts used in the treatment of hydrocephalus: the need for a servo-valve shunt. Dev Med Child Neurol,15: pp.646-653.

[5] Maixner, WJ. et al. (1990). Ventricular volume in infantile hydrocephalus and its relationship to intracranial pressure and cerebrospinal fluid clearance before and after treatment. Apreliminary study. Pediatr Neurosurg,16(4-5): pp. 191-196.

[6] Rekate, HL. (1994). The usefulness of mathematical modeling in hydrocephalus research. Childs Nerv Syst, 10(1): pp. 13-18.

[7] Boon, AJ. et al. (1998). Dutch Normal-Pressure Hydrocephalus Study: randomized comparison of low- and medium-pressure shunts. J Neurosurg, 88(3): pp. 490-4959.

[8] McQuarrie, IG.; Saint-Louis, L. \& Scherer, PB. (1984). Treatment of normal pressure hydrocephalus with low versus medium pressure cerebrospinal fluid shunts. Neurosurgery, 15(4): pp. 484-488.

[9] Zemack, G. et al. (2003). Clinical experience with the use of a shunt with an adjustable valve in children with hydrocephalus. J Neurosurg, 98(3): pp. 471-476.

[10] Zemack, G. \& Romner, B. (2000). Seven years of clinical experience with the programmable Codman Hakim valve: a retrospective study of 583 patients. J Neurosurg, 92(6): pp. 941-948.

[11] Pollack, IF.; Albright, AL. \& Adelson, PD. ( 1999). A randomized, controlled study of a programmable shunt valve versus a conventional valve for patients with hydrocephalus. Hakim-Medos Investigator Group. Neurosurgery, 45(6): pp. 1399_ 1408; discussion pp. 1408-1411.

[12] Aschoff, A. et al. ( 1995). Overdrainage and shunt technology. A critical comparison of programmable, hydrostatic and variableresistance valves and flow-reducing devices. Childs Nerv Syst, 11 (4): pp. 193-202.

[13] Trost, HA. et al. (1991). Testing the hydrocephalus shunt valve: long-term bench test results of various new and explanted valves. The need for model for testing valves under physiological conditions. Eur J Pediatr Surg, 1(Suppl 1): pp. 38-40.

[14] Kestle, J. \& Walker, M. (2005). A multicenter prospective cohort study of the Strata valve for the management of hydrocephalus in pediatric patients. J Neurosurg, 102 (Suppl 2): pp. 141-145.

[15] Drake, JM.; da Silva, MC. \& Rutka, JT. (1993). Functional obstruction of an antisiphon device by raised tissue capsule pressure. Neurosurgery, 32(1): pp. 137-139.

[16] Lumenta, CB.; Roosen, N. \& Dietrich, U. (1990). Clinical experience with a pressureadjustable valve SOPHY in the management of hydrocephalus. Childs Nerv Syst, 6(5): pp. 270-274.

[17] Piatt, JH Jr. (1995). Cerebrospinal fluid shunt failure: late is different from early. Pediatr Neurosurg, 23(3): pp. 129-133.

[18] Matsumae, M. et al. (1989). Quantification of cerebrospinal fluid shunt flow rates. Assessment of the programmable pressure valve. Childs Nerv Systx, 5(6): pp. 356360.

[19] Faulhauer, K. Schmitz, P. (1978). Overdrainage phenomena in shunt treated hydrocephalus. Acta Neurochir, 45: pp. 89-101. 
[20] Pudenz, RH. Foltz, EL. (1991). Hydrocephalus: overdrainage by ventricular shunts. A review and recommendations. Surg Neurol, 35(3): pp. 200-212.

[21] Kamiryo, T. et al. (1991). Intracranial pressure monitoring using a programmable pressure valve and a telemetric intracranial pressure sensor in a case of slit ventricle syndrome after multiple shunt revisions. Childs Nerv Syst, 7(4): pp. 233234. 


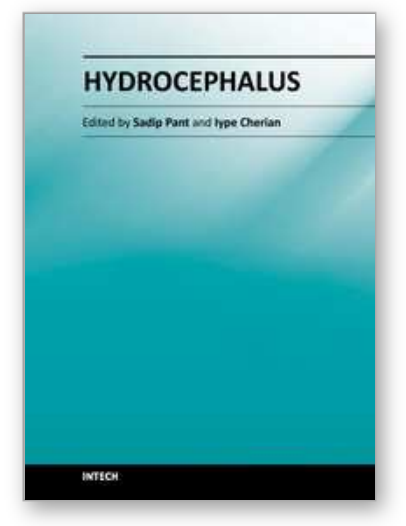

\author{
Hydrocephalus \\ Edited by Dr Sadip Pant
}

ISBN 978-953-51-0162-8

Hard cover, 214 pages

Publisher InTech

Published online 24, February, 2012

Published in print edition February, 2012

Description of hydrocephalus can be found in ancient medical literature from Egypt as old as 500 AD.

Hydrocephalus is characterized by abnormal accumulation of cerebrospinal fluid (CSF) in the ventricles of the brain. This results in the rise of intracranial pressure inside the skull causing progressive increase in the size of the head, seizure, tunneling of vision, and mental disability. The clinical presentation of hydrocephalus varies with age of onset and chronicity of the underlying disease process. Acute dilatation of the ventricular system manifests with features of raised intracranial pressure while chronic dilatation has a more insidious onset presenting as Adams triad. Treatment is generally surgical by creating various types of cerebral shunts. Role of endoscopic has emerged lately in the management of hydrocephalus.

\title{
How to reference
}

In order to correctly reference this scholarly work, feel free to copy and paste the following:

Yasuo Aihara (2012). Novel Method for Controlling Cerebrospinal Fluid Flow and Intracranial Pressure by Use of a Tandem Shunt-Valve System, Hydrocephalus, Dr Sadip Pant (Ed.), ISBN: 978-953-51-0162-8, InTech, Available from: http://www.intechopen.com/books/hydrocephalus/novel-method-for-controlling-cerebrospinalfluid-flow-and-intracranial-pressure-by-use-of-a-tandem-s

\section{INTECH}

open science | open minds

\section{InTech Europe}

University Campus STeP Ri

Slavka Krautzeka 83/A

51000 Rijeka, Croatia

Phone: +385 (51) 770447

Fax: +385 (51) 686166

www.intechopen.com

\section{InTech China}

Unit 405, Office Block, Hotel Equatorial Shanghai

No.65, Yan An Road (West), Shanghai, 200040, China 中国上海市延安西路65号上海国际贵都大饭店办公楼 405 单元

Phone: +86-21-62489820

Fax: +86-21-62489821 
(C) 2012 The Author(s). Licensee IntechOpen. This is an open access article distributed under the terms of the Creative Commons Attribution 3.0 License, which permits unrestricted use, distribution, and reproduction in any medium, provided the original work is properly cited. 